\title{
DEEP-SEATED SARCOMAS OF THE PENIS
}

\author{
ALBERTO A. ANTUNES, LUCIANO J. NESRALLAH, PIERRE D. GONCALVES, YURI A. \\ FERREIRA, JOAO C. CAMPAGNARI, MIGUEL SROUGI \\ Portuguese Beneficence Hospital of Sao Paulo and Syrian Lebanese Hospital, Sao Paulo, SP, Brazil
}

\begin{abstract}
Mesenchymal neoplasias represent $5 \%$ of tumors affecting the penis. Due to the rarity of such tumors, there is no agreement concerning the best method for staging and managing these patients.

Sarcomas of the penis can be classified as deep-seated if they derive from the structures forming the spongy body and the cavernous bodies. Superficial lesions are usually low-grade and show a small tendency towards distant metastasis. In contrast, deep-seated lesions usually show behavior that is more aggressive and have poorer prognosis.

The authors report 3 cases of deep-seated primary sarcomas of the penis and review the literature on this rare and aggressive neoplasia.
\end{abstract}

Key words: penis; sarcoma; neoplasm metastasis

Int Braz J Urol. 2005; 31: 245-50

\section{INTRODUCTION}

Cancer of the penis is infrequent, with an incidence ranging from 0.6 to $1 / 100,000$ patients in developed countries. Epidermoid carcinoma is the dominant histological type; however, other tumors, including basal cell carcinoma and melanoma, can be found as well (1). Malignant and benign mesenchymal tumors represent $5 \%$ of tumors affecting this organ (2).

The sarcomas of the penis can be classified as superficial or deep-seated according to the tissues from which they derive (3). Superficial lesions rarely reach deep tissues, are usually low-grade and show a small tendency to distant metastases. In contrast, deepseated lesions, which include those originating from the glans, those involving the smooth muscle of the spongy and/or cavernous bodies, and those representing advanced lesions that were initially superficial, usually show more aggressive behavior and have poorer prognosis (4).
In the present study, the authors report 3 cases of primary deep-seated sarcomas of the penis and review the literature on this rare and aggressive neoplasia.

\section{CASES REPORT}

\section{Case 1}

A 61-year old Caucasian man presented penile pain and a tumor at the base of the penis for 60 days. Physical examination of the penis revealed a constant state of semi-erection, which the patient reported as having started 30 days earlier. On palpation, a tumor mass with hardened consistency was observed in the pre-pubic region measuring approximately $5 \mathrm{~cm}$ in diameter and extending to the right cavernous body and perineal region.

Laboratory tests, chest x-ray and abdominal ultrasound (USG) were normal. Magnetic resonance imaging (MRI) of the pelvis showed a solid infiltrative mass at the base of the penis and signs suggestive of 
thrombosis in the cavernous bodies (Figure-1). There was no evidence of enlarged lymph nodes.

The patient underwent emasculation (Figure2) and definitive suprapubic cystostomy with closure of the urethral stump at the level of the membranous urethra due to the perineal extension of the tumor. There were no postoperative complications and the patient was discharged from the hospital on the 4th postoperative day. Pathological examination revealed leiomyosarcoma involving the cavernous bodies and extending to the deep perineal planes (Figure-3). Surgical margins were free from neoplasia.

One month following surgery, patient presented respiratory stress and the radiological examination revealed the presence of bilateral pulmonary nodules and metastases characteristics. Chemotherapy was then started with adriamycin, ifosfamide and dimethy-1-triazeno-imidazol-

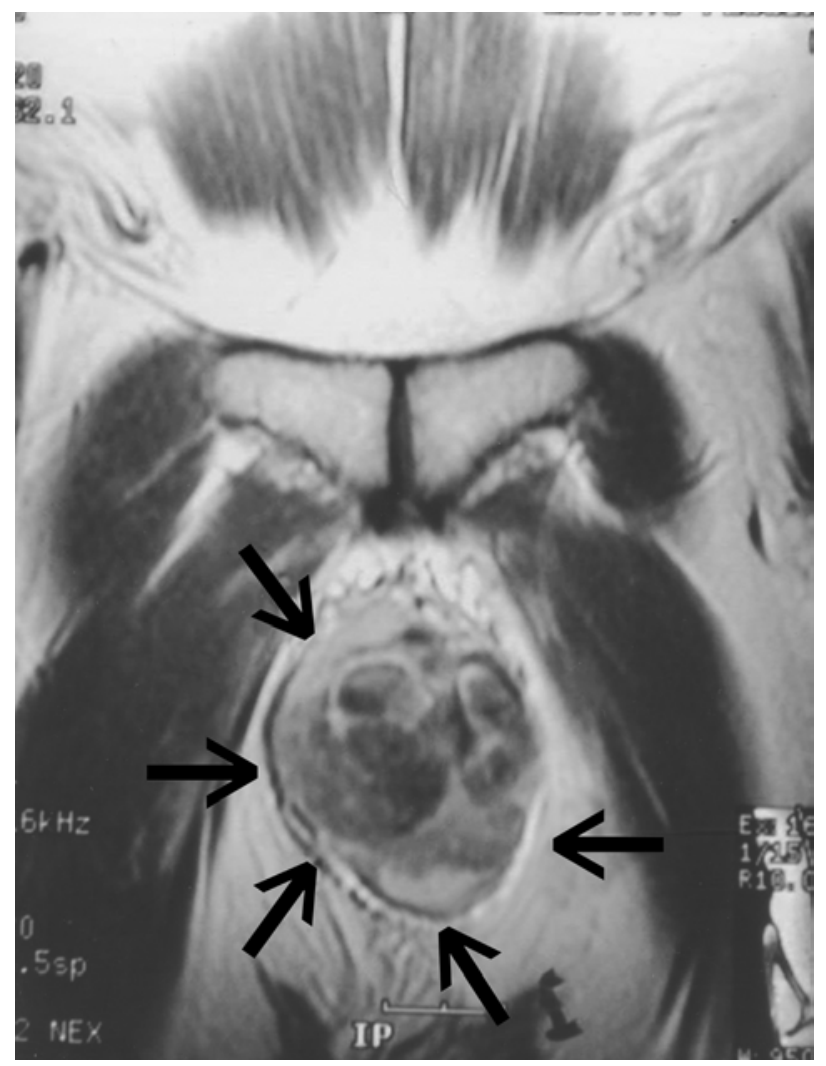

Figure 1 - Magnetic resonance imaging. The coronal T1weighted image of the base of the penis shows an infiltrative tumor leading to destruction of cavernous bodies (arrows).

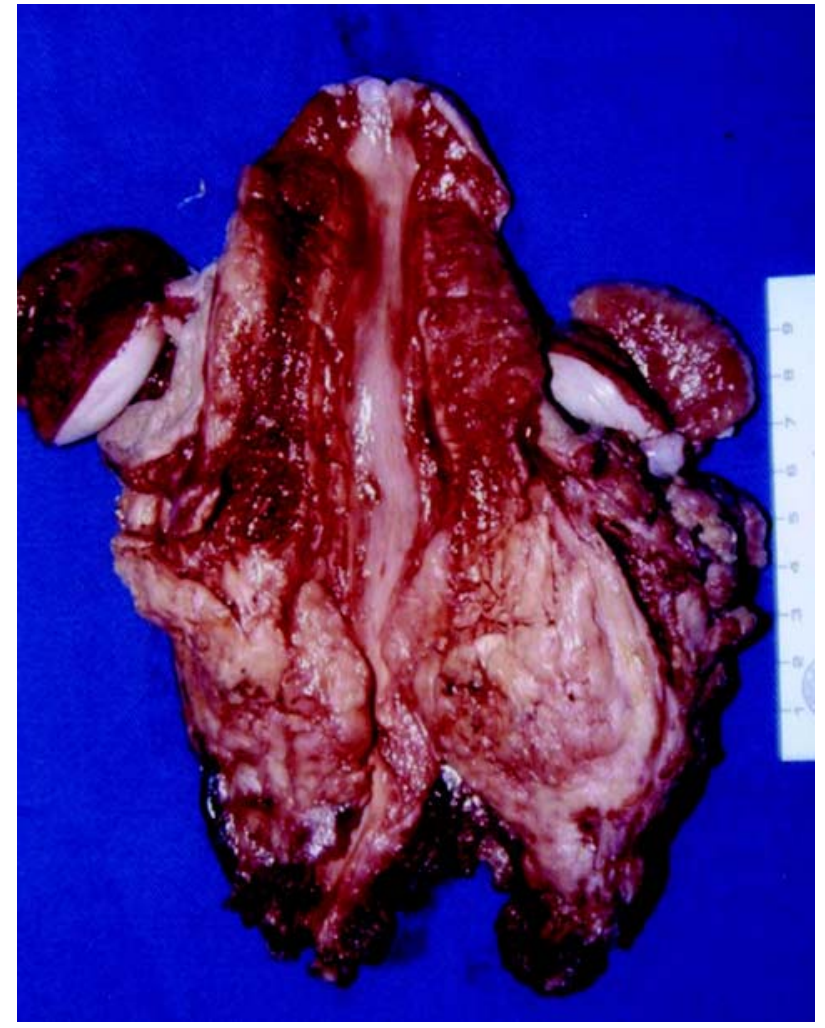

Figure 2 - Emasculation. Resection of the entire penis and scrotum.

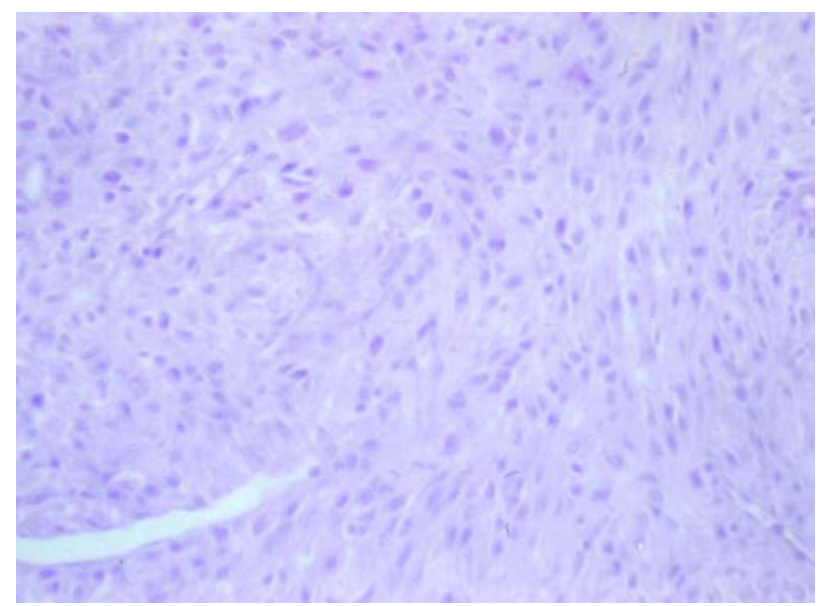

Figure 3 - Leiomyosarcoma of the penis (HE, X100).

carboxamide (DTIC). Upon completion of chemotherapy, the patient presented a reduction in pulmonary lesions but he died in the eighth postoperative month. 


\section{Case 2}

A 56-year old man complained of a painful perineal tumor for 2 months. Physical examination revealed a fixed perineal mass measuring approximately $6.0 \mathrm{~cm}$ in diameter.

Pelvic computerized tomography revealed a solid nodule measuring $6.5 \mathrm{~cm}$ with involvement of cavernous bodies. Laboratory tests were normal, as were radiological examinations of the chest and abdomen.

Emasculation was performed with closure of the urethral stump followed by definitive cystostomy. The patient evolved with no intercurrences and was discharged from the hospital on the 5 th postoperative day.

The pathological examination revealed leiomyosarcoma of cavernous bodies with involvement of surgical margins. The patient was then referred to adjuvant radiotherapy, however he complained of respiratory stress and control exams evidenced pulmonary nodules suggestive of metastases at the end of the treatment. Systemic chemotherapy was indicated, but the patient died in the 9th postoperative month.

\section{Case 3}

A 72-year old man presented perineal discomfort with increasing severity for approximately 6 months, especially during sexual intercourse. He reported the appearance of a tumor in the penis 30 days earlier. Physical examination revealed a hardened mass measuring approximately $8.0 \times 8.0 \mathrm{~cm}$ located at the base of the penis, infiltrating to the cavernous bodies and extending to the perineum.

Laboratory tests were normal and pelvic ultrasound showed no abnormalities. Abdominal and pelvic computerized tomography showed a solid lesion in cavernous bodies measuring $5.9 \mathrm{~cm}$ in diameter. MRI allowed a more accurate assessment of the local extension to the perineum (Figure-4). There was no evidence of enlarged lymph nodes in the chest $\mathrm{x}$-ray.

The patient underwent emasculation where an extensive involvement was observed in the perineum and right ischiorectal fossa. Again, suprapubic definitive cystostomy was performed.

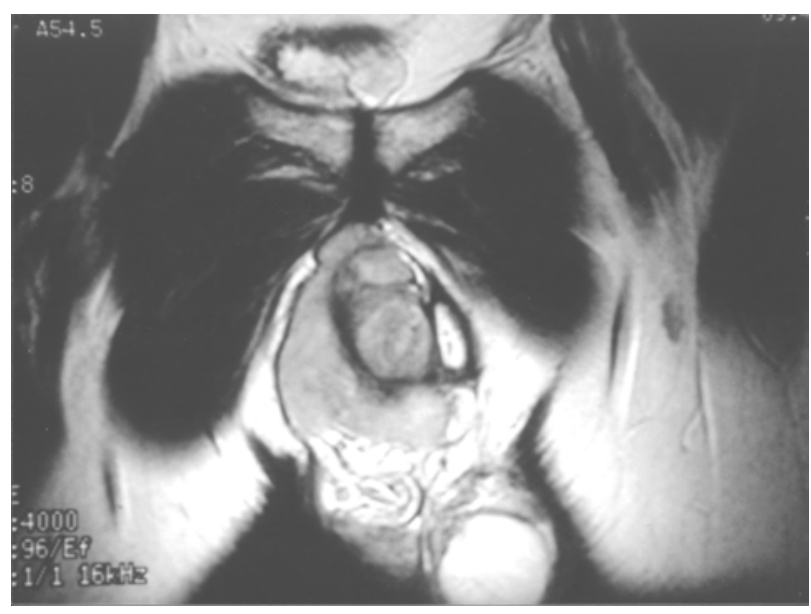

Figure 4-Magnetic resonance imaging. Coronal T1-weighted image shows tumor in soft tissues affecting the root of the right cavernous body and extending to the pubis.

There were no postoperative complications and the patient was discharged from hospital on the 5th postoperative day.

The pathological study together with an immunohistochemical analysis revealed a fibrohistiocytic sarcomatous tumor (Figure-5) with imprecise limits located $0.8 \mathrm{~cm}$ from the surgical margins. The patient received adjuvant radiotherapy; however, pulmonary metastasis was diagnosed in the 3rd postoperative month. The patient received

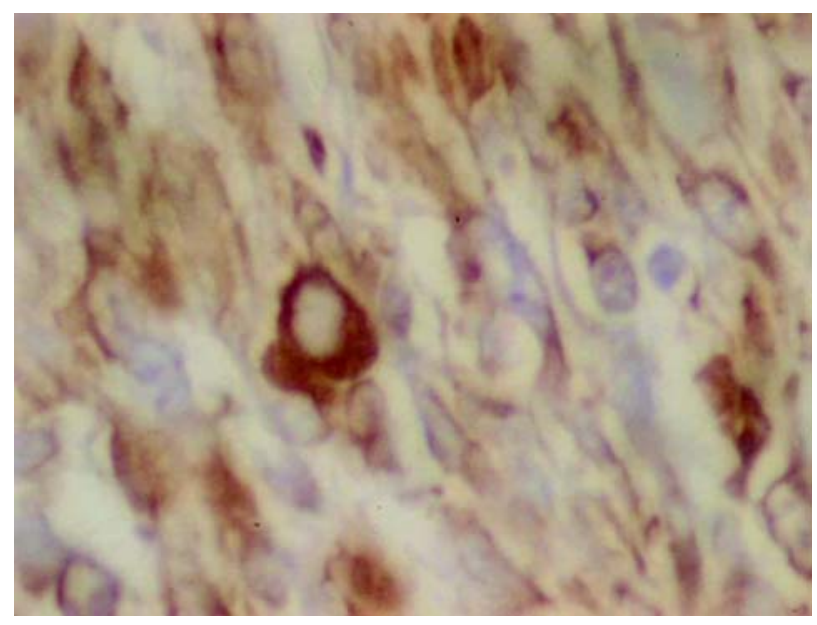

Figure 5 - Malignant fibrohistiocytoma of the penis. Immunohistochemical analysis for CD-68 (X400). 
chemotherapy, which was unsuccessful, and died on the 6 th postoperative day.

\section{COMMENTS}

It is estimated that less than 5\% of soft tissue sarcomas originate from the urogenital tract, and they represent only 1 to $2 \%$ of neoplasias in this system (5). In the present study, we present 3 cases of deepseated sarcomas of the penis in patients aged between 56 and 72 years old that were diagnosed based on clinical presentation and pelvic imaging studies. The cases reflect the lesion's aggressive characteristics leading to death after a mean period of 7.6 months despite aggressive surgical treatment and adjuvant therapy.

Despite being rare, some characteristics relative to the pattern of recurrence and metastatic dissemination for sarcomas of the penis have been well established. Local recurrence seems to be a frequent phenomenon, and total amputation of the penis should be considered even for superficial lesions (6). On the other hand, regional metastases appear to occur less frequently, and if there is no apparent lymph nodal disease, lymphatic dissection is not recommended (7). The most frequent sites of distant metastases are the lungs, liver and brain (8).

The best treatment method for sarcomas is complete resection of the tumor. One study showed that no patient with retroperitoneal sarcoma had survived beyond 5 years when the sarcomas had not been not completely resected, while the 5-year survival rate for patients who underwent complete resection was $48 \%$ (9). When investigating 43 patients with urogenital sarcoma, Russo et al. (10) reported that complete tumor resection was possible in $72 \%$ of the cases, and $58 \%$ had disease-free margins. Survival rates after 3 and 5 years were 55\% and $40 \%$ respectively. Another factor that contributes to the poor prognosis in these patients is the fact that no effective response to adjuvant therapy has been obtained up to this moment. Radiotherapy has been used for final control in local disease for unresectable tumors and for patients with positive margins, with chemotherapy being reserved for cases of disseminated disease. In the series by Russo et al. (10), no patient with disseminated disease was fully responsive to the use of several chemotherapy regimens.

Some previously described prognostic factors can help to predict the biological behavior of sarcomas of the penis (10). These factors are lesion size (larger or smaller than $5 \mathrm{~cm}$ ), extension of invasion (superficial vs. deep-seated), complete resection of the lesion, presence or absence of metastatic disease and expression of the retinoblastoma gene (11).

Two of the 3 cases described in this study were diagnosed as leiomyosarcoma. In 1994, 14 cases of deep-seated leiomyosarcomas of the penis were reviewed (12). The lesions were primarily treated with local excision (3), amputation (8), external radiotherapy (2) and chemotherapy (1), and patients were followed during a period from 1 to 72 months (mean 16 months). Eight patients died during follow-up. Among the patients treated by radical surgery (amputation), 3 developed disseminated disease and 4 died from the disease. All patients treated with chemotherapy or radiotherapy had local recurrence, with 2 of them presenting disseminated disease.

More recently, Fetsch et al. (13) reported 14 cases of leiomyosarcoma of the penis from a single center. Ages ranged from 43 to 62 years old (mean 51). The penile shaft was the most frequently affected site. The size of the lesions ranged between 0.5 and $6 \mathrm{~cm}$. Nine tumors were superficial, $2 \mathrm{had}$ undetermined location, and 3 were deep-seated. Immunohistochemical analysis was available for 9 patients (64\%), and immunoreactivity for desmin was present in all such cases. Mean follow-up was 12 years and 11 months, and, of 9 patients (64\%) with available information, 3 had multiple local recurrences, 2 of which were subsequently treated by wide local excision and partial penectomy. The third patient refused treatment and developed distant metastasis 10 months after the fourth recurrence. The main prognostic factors were the lesion's depth and size.

The third case was diagnosed as a fibrohistiocytic sarcoma. Despite being the sarcoma that is more frequently described in the elderly, this histological type rarely involves the urogenital tract 
(14). Only 2 cases of malignant fibrohistiocytoma have been described up to the present time $(15,16)$. These tumors usually display an aggressive behavior tending to lymphatic dissemination $(15,17)$. Regional lymphadenectomy apparently does not benefit those patients with sarcomas of the penis without evidence of lymphatic dissemination, however it is highly recommended for patients with this type of tumor. In the presence of metastases, chemotherapy seems to present some benefits (18).

Other types of penile sarcoma have been described in the literature. According to records from the Armed Forces Institute of Pathology, Kaposi's sarcoma is the most common histological type, surpassing the cases of leiomyosarcoma by a 2:1 ratio. In contrast to the latter, the Kaposi's sarcomas are strongly reactive to $\mathrm{CD} 34$ and $\mathrm{CD} 31$ and do not show desmin expression. Finally, sarcomatoid carcinomas must always be remembered when a penile sarcoma is diagnosed. The immunohistochemical analysis for keratin pattern and extension can distinguish between both tumors (13).

Though radical surgery with negative margins is the treatment that provides the best results, our patients quickly evolved to disseminated disease, with the lungs being the most frequent site for metastasis. When a perineal urethrostomy is impossible, and if the patient's clinical conditions allow, performing a continent urinary shunt might make social living more acceptable for these patients, since they would not have to use a cystostomy bag (19).

The authors conclude that sarcomas of penis are rare tumors and usually have poor prognosis when they involve deep-seated lesions. The analysis of prognostic factors can help to identify those patients at higher risk for disease progression. The complete tumor resection with negative surgical margins whenever possible seems to offer the best chances of healing. No effective treatment for disseminated disease has been developed up to the present time.

\section{REFERENCES}

1. Dehner LP, Smith BH: Soft tissue tumors of the penis. A clinicopathologic study of 46 cases. Cancer. 1970; 25: 1431-47.
2. Lucia MS, Miller GJ: Histopathology of malignant lesions of the penis. Urol Clin North Am. 1992; 19: 227-46.

3. Pratt RM, Ross RT: Leiomyosarcoma of the penis. A report of a case. Br J Surg. 1969; 56: 870-2.

4. Trojani M, Contesso G, Coindre JM, Rouesse J, Bui NB, de Mascarel A, et al.: Soft-tissue sarcomas of adults; study of pathological prognostic variables and definition of a histopathological grading system. Int J Cancer. 1984; 33: 37-42.

5. Herr HR: Sarcomas of the Urinary Tract. In: de Kernion JB, Paulson DF (eds.), Genitourinary Cancer Management. Philadelphia, Lea \& Febiger. 1987; pp. 259-70.

6. Webber RJ, Alsaffar N, Bissett D, Langlois NE: Angiosarcoma of the penis. Urology. 1998; 51: 1301 .

7. Lynch Jr. DF, Pettaway CA: Tumors of the Penis. In: Walsh PC, Retik AB, Vaughan Jr. ED, Wein AJ (eds.), Campbell's Urology, 8th ed. Philadelphia, WB Saunders. 2002; pp. 2945-81.

8. Antoneli CB, Novaes PE, Alves AC, Cardoso H, Lopes A: Rhabdomyosarcoma of the penis in a 15month-old boy. J Urol. 1998; 160: 2200-1.

9. Zhang G, Chen KK, Manivel C, Fraley EE: Sarcomas of the retroperitoneum and genitourinary tract. J Urol. 1989; 141: 1107-10.

10. Russo P, Brady MS, Conlon K, Hajdu SI, Fair WR, Herr HW et al.: Adult urological sarcoma. J Urol. 1992; 147: 1032-6; discussion 1036-7.

11. Cance WG, Brennan MF, Dudas ME, Huang CM, Cordon-Cardo C: Altered expression of the retinoblastoma gene product in human sarcomas. $\mathrm{N}$ Engl J Med. 1990; 323: 1457-62.

12. Pow-Sang MR, Orihuela E: Leiomyosarcoma of the penis. J Urol. 1994; 151: 1643-5.

13. Fetsch JF, Davis Jr CJ, Miettinen M, Sesterhenn IA: Leiomyosarcoma of the penis: a clinicopathologic study of 14 cases with review of the literature and discussion of the differential diagnosis. Am J Surg Pathol. 2004; 28: 115-25.

14. Enzinger FM, Weiss SW: Soft Tissue Tumors. St Louis, Mosby. 1983; pp. 116-98.

15. Parsons MA, Fox M: Malignant fibrous histiocytoma of the penis. Eur Urol. 1988; 14: 75-6.

16. Fletcher CD, Lowe D: Inflammatory fibrous histiocytoma of the penis. Histopathology. 1984; 8: 1079-84.

17. Sclama AO, Berger BW, Cherry JM, Young JD Jr: Malignant fibrous histiocytoma of the spermatic cord: 


\section{SARCOMAS OF THE PENIS}

the role of retroperitoneal lymphadenectomy in management. J Urol. 1983; 130: 577-9.

18. Williamson JC, Johnson JD, Lamm DL, Tio F: Malignant fibrous histiocytoma of the spermatic cord. J Urol. 1980; 123: 785-8.
19. Lemelle JL, Simo AK, Schmitt M: Comparative study of the Yang-Monti channel and appendix for continent diversion in the Mitrofanoff and Malone principles. J Urol. 2004; 172: 1907-10.

Received: January 17, 2005 Accepted after revision: May 3, 2005

Correspondence address:

Dr. Alberto Azoubel Antunes

Rua Três de Maio, 17/31

São Paulo, SP, 04044-020, Brazil

Phone: + 5511 5573-5385

E-mail: betoazoubel@yahoo.com.br 